\title{
EDUCACIÓN PARA LA CALIDAD \\ DE VIDA DE LAS PERSONAS CON \\ DISCAPACIDAD INTELECTUAL
}

Dra. Elsa R. Bustamante Quiroz

Directora del Instituto de Investigación de la UMCH

\section{Resumen}

En este artículo se revisan los conceptos de calidad de vida y autodeterminación para proponer, luego, estrategias que favorezcan la construcción de una escuela verdaderamente inclusiva orientada al logro de la calidad de vida.

Palabras claves: Calidad de vida, Autodeterminación, Discapacidad intelectual, educación inclusiva

\section{Summary}

In this article we review the concepts of quality of life and self-determination in order to propose strategies that favor the development of a truly inclusive school oriented to acquiring quality of life.

Key words: Quality of life, Self-determination, Intellectual disability, inclusive education

\section{Introducción}

El concepto de calidad de vida como referente y guía para la provisión de servicios comienza a gestarse en el ámbito internacional hacia inicios de la década de los sesenta. En el campo de la atención educativa a las personas con discapacidad intelectual, constituye el peldaño más elevado en un proceso que se inicia con el afán de mejorar las condiciones de vida de las personas institucionalizadas; que continúa en los años setenta promoviendo la desinstitucionalización, basándose en el principio de la normalización, y que, en las últimas décadas, propugna la participación plena en la comunidad sirviéndose de sistemas de apoyos. 
La educadores que realizan su tarea desde el enfoque de la calidad de vida han de tener presente que el bienestar emocional, la libertad y autonomía, la formulación de proyectos y el encontrar sentido a la existencia son metas deseadas por todos los seres humanos, y, siendo consciente de ello, han de buscar desarrollar en los niños, desde sus primeros años, las capacidades que les permitan llegar a ser protagonista de su existencia.

\section{¿Qué se entiende por calidad de vida?}

Aunque su aparición en las políticas sociales y el interés que ha generado en la investigación científica son relativamente recientes, la calidad de vida como aspiración del hombre está ligada a su historia y se puede percibir su búsqueda desde las primeras manifestaciones culturales. Según Asensio, Bárcena y Mélich (200I) la expresión calidad de vida "no deja de ser en la actualidad más que la versión 'menor', descreída, postmoderna diríamos, de otra más ampulosa y resbaladiza cual es la de 'felicidad'" (p. 82).

Al igual que después de siglos de reflexión cuidadosa y de trabajo minucioso de filósofos, científicos y del hombre común, el concepto de felicidad se escabulle ante la intención de delimitarlo, el concepto de calidad de vida se presenta aún ambiguo debido a que está ligado a los avatares de la existencia y a la autopercepción.

No obstante, parece haber un acuerdo entre los estudiosos en considerarlo un concepto muldimensional que abarca elementos objetivos (indicadores externos) y elementos subjetivos, que centran la atención más allá de las condiciones físicas en las percepciones de las personas acerca de su estado de bienestar. En un estudio realizado por Hughes, Hwang, Kim, Eisenman y Killian (citado por Gómez-Vela, Verdugo y Canal, 2002) se encontraron I 5 dimensiones que aparecían con frecuencia en las diferentes aproximaciones conceptuales: bienestar psicológico y satisfacción personal; empleo; autodeterminación, autonomía y elección personal; ocio y tiempo libre; competencia personal, ajuste comunitario y habilidades para la vida independiente; ambiente residencial; integración comunitaria; normalización; apoyo recibido de los servicios; indicadores sociodemográficos individuales; desenvolvimiento y realización personal: aceptación social, estatus social y ajuste ecológico; bienestar físico y material; y responsabilidad cívica. Por su parte, Schalock y Verdugo (2007) consideran ocho dimensiones en el concepto: desarrollo personal, autodeterminación, relaciones interpersonales, inclusión social, derechos, bienestar emocional, bienestar físico y bienestar material.

Como se puede apreciar, no se concibe la calidad de vida al margen de la satisfacción de las necesidades objetivas. La falta de recursos para cubrir las necesidades alimenticias de forma balanceada, la permanencia en alojamientos que no protegen, 
el limitado acceso a los servicios de salud y a los productos farmacológicos requeridos, que son situaciones ligadas a la adversidad socioeconómica, se muestran como factores importantes en el incremento de riesgo de depresión y otros problemas de salud mental (Reading y Reynolds, 200 I). Por lo tanto, no se puede hablar de calidad de vida cuando existen serias carencias materiales, pero, no se puede, tampoco, identificar el bienestar material con aquella; como lo explican Asensio et al. (200 I):

Ya Epicuro, Aristóteles o Séneca nos advertían, desde su privilegiada posición social, que sin cierto grado de riquezas resulta difícil el logro de la felicidad. No obstante, entendemos que la materialidad que nos rodea no explica lo esencial de nuestras respectivas vidas, susceptibles de experimentarse plenas en la precariedad y profundamente insatisfactorias en la abundancia. (p. 85)

Dice Fullat (2000) que la capacidad del hombre de poder tomar conciencia de lo dado le abre a lo posible, a lo todavía-no-dado. Por esto, transcendiendo lo real, la vida humana es posibilidad, es proyecto, algo que no está previamente determinado sino que es un constante quehacer; surge entonces la pregunta por el sentido, por el para qué del existir. El advertir cómo se corresponde lo que se hace con el sentido que se le ha dado a la existencia, permite desarrollar una sensación de bienestar asociada con la percepción subjetiva de la calidad de vida.

\section{Sentido de la vida en personas con discapacidad intelectual}

Según Frankl (1984), la posibilidad de encontrar sentido en la vida no depende del sexo, ni del coeficiente intelectual, ni del nivel de formación. La frase de un joven autista, citada por Frith ( 199 I) "Todo me pone triste, porque me estoy haciendo cada vez mayor y sigo sin encontrar a nadie.... Ojalá que alguien que pueda ofrecerme cariño y afecto, lo haga" (p. 193), así como los proyectos de las personas con discapacidad intelectual contemplados por quienes viven cerca de ellos, estarían indicando la necesidad de darle coherencia y una orientación general a la existencia, es decir de encontrarle un sentido.

A lo largo de los años, con el afán de proteger a las personas con discapacidad intelectual, desde la presunción de saber mejor que ellas lo que es necesario en sus vidas, se ha ido limitando y, más aún, cercenando lo más íntimo que como personas poseen: su libertad moral, su capacidad de elaborar y proponer sus planes de vida y llevarlos a la práctica.

La tarea educativa, entendida como el acompañamiento al ser humano en el proceso de realización plena, exige replantearse la atención que se le ha venido dando a 
la persona con discapacidad intelectual; es necesario resaltar la importancia de una educación que la contemple en su integridad, con su necesidad de trascendencia y voluntad de sentido.

\section{Autodeterminación y calidad de vida}

Un factor especialmente relevante de la calidad de vida es la autodeterminación, muy estudiada últimamente por quienes trabajan en el campo de la discapacidad. La autodeterminación es definida por Wehmeyer (2005) como "las acciones volitivas que capacitan a la persona para actuar como el principal agente causal de su propia vida y mantener o mejorar su calidad de vida" (p. I I7).

La autodeterminación presenta cuatro características: autonomía, autorregulación, desarrollo psicológico (capacitación) y autorrealización. Estas características se desarrollan a partir de la adquisición, durante la niñez y la adolescencia, de los diferentes componentes de la conducta autodeterminada, como son: hacer elecciones, resolver problemas, tomar decisiones, poner y alcanzar objetivos, autodefensa y habilidades de autocontrol (Wehmeyer, 2009).

La adquisición de estos componentes por parte de la persona con discapacidad intelectual va a exigir de los educadores un compromiso concreto con la construcción de ambientes que la favorezcan. No se puede esperar que un adulto al que desde pequeño se le han solucionado los problemas, se ha elegido por él, se ha decidido por él, se le han impuesto límites, se le ha organizado la vida, adquiera, repentinamente, la posibilidad de autodeterminarse. Como señalan Peralta y Arellano (20 I4) se requieren ambientes educativos que posibiliten su participación activa y su protagonismo en las decisiones importantes de sus vidas.

\section{Educación para la calidad de vida}

Este enfoque que toma como referencia para la dotación de servicios educativos a la calidad de vida, exige de la escuela una orientación hacia su logro, desde los primeros años, como se ha señalado. Verdugo (2009) sostiene que esto es coherente con el principio de que la educación inclusiva no se limita a las exigencias académicas y que adoptarlo implicará un cambio social para involucrar a los diferentes agentes en la búsqueda de oportunidades y experiencias en el entorno comunitario.

La escuela inclusiva peruana no ha satisfecho las expectativas de quienes veían en ella una solución al problema de la segregación, aunque sí representa un paso hacia adelante, a pesar de haber tropezado con múltiple dificultades aún no superadas (Ministerio de Educación [MINEDU], 20 I2). 
Uno sus mayores logros ha sido el enriquecimiento moral y afectivo de los niños, de los profesionales y de las familias que han formado parte de ella, ya que han empezado a percibir la diferencia como un elemento enriquecedor de la convivencia humana, lo que permitirá una visión holística de la discapacidad y un abordaje integral de su problemática. Sin embargo, matricular a un niño con discapacidad en una institución de educación básica regular, no garantiza que se beneficiará de una educación inclusiva:

La segregación y el etiquetaje no han sido, lamentablemente, características exclusivas de la escuela especial; en las aulas inclusiva el niño con discapacidad ha sido visto muchas veces como el "lento" de la clase o simplemente como "el niño inclusivo". Si no logra acceder al lenguaje que se maneja en el aula, a la construcción social de significados a los que acceden los compañeros, si no comprende el lenguaje que mediatiza las enseñanzas y las relaciones sociales, se puede sentir excluido de ellas.

Por otra parte, se observa que instituciones que en Lima se dedican a ofrecer servicios de educación inclusiva en colegios regulares, en la práctica aplican lo que corresponde a la integración, no a la inclusión: una profesora de apoyo, que puede ser especialista en educación especial o estudiante de educación, con un uniforme propio de su institución, acompaña al "niño inclusivo" en el interior de un aula regular. ¿Qué efecto tiene este tipo de actuación en el desarrollo emocional y cognitivo del niño con discapacidad?, ¿cuántos niños y adolescentes derivados desde escuelas especiales a escuelas regulares han desertados? y ipor qué lo han hecho?, ise sienten cómodos los niños con discapacidad en las aulas regulares?, son algunas preguntas que solo podrán responderse si se escucha la voz de los implicados.

Si la escuela peruana desea ser realmente inclusiva deberá potenciar prácticas educativas que favorezcan el desarrollo de la autodeterminación y que tenga como norte la calidad de vida.

Le corresponde a la escuela propiciar un clima por el que los niños y los adolescentes con discapacidad encuentren afecto en la experiencia diaria, para que puedan, así, comprender que ellos son importantes, aprendan a valorarse a sí mismos y a los demás, y a ver la vida con optimismo. En este ambiente, las actividades educativas deben favorecer las experiencias de éxito, pero de éxitos conseguidos con esfuerzo. Bandura (1999) afirma que un poderoso incentivo para el desarrollo y para el control personal es tener la posibilidad de producir resultados valiosos y prevenir los indeseables. Por su parte, Seligman (1989) sostiene que lo que genera en la persona disminución de la fuerza del yo es la sensación de falta de control sobre lo que le 
acontece, ya sean estos acontecimientos traumáticos o positivos. No se debe, por tanto, tratar de proteger al niño o al adolescente con discapacidad impidiendo toda situación que pueda resultarle problemática; él necesita aprender que tiene control sobre sus circunstancias. Los esfuerzos de dominio independiente que permiten conseguir los objetivos planteados, contando con el apoyo de adultos significativos que demuestran su reconocimiento en forma consistente, es lo que favorece el desarrollo de su autoeficacia y de una motivación intrínseca para enfrentar las dificultades con seguridad, esfuerzo y persistencia.

Le corresponde a la escuela, también, involucrar en la educación de las personas con discapacidad a toda la comunidad: el barrio, la parroquia, los clubes, el hospital, serán espacios para brindar entrenamiento en la autobservación, autoevaluación, y autorrefuerzo, en la autoeficacia y el autoconocimiento, en el establecimiento de metas y la adquisición de habilidades. Lo que se requiere es una Escuela Inclusiva que sobrepase sus muros, una escuela cuyos recursos, materiales y humanos, sean los recursos de la comunidad (llámense servicios especializados de los centros de salud, centros de formación profesional, clubes, etc.), donde las aulas sean las casas del barrio y las empresas, es decir, que sea capaz de coordinar y dirigir la educación de sus estudiantes en espacios diferentes a los del centro educativo y con un currículum que no se ciña a los paradigmas establecidos por la tradición escolar.

Sin embargo, las limitaciones más significativas a una verdadera educación inclusiva, orientada a la calidad de vida, no se focalizan en el campo escolar; quizá las máximas barreras se encuentran en el concepto de discapacidad y de "éxito" que se maneja desde fuera de la escuela y en la convicción de que la tarea de esta es preparar a sujetos que puedan insertarse en el engranaje social.

La atención a la persona con discapacidad intelectual actualmente aún trasluce la prevalencia del modelo médico de la discapacidad. Como afirma Vehmas (2004) "Las intervenciones son señaladas solamente en el individuo, quien es considerado como anormal, mientras la comunidad circundante es intocable" (p. 5I). Tamarit (2005) se ubica con quienes opinan que un factor importante en esta visión es la concepción aristotélica que considera a lo racional como el elemento que diferencia al ser humano de los otros seres vivos, ocasionando que

Aquellos que no alcanzan el nivel de raciocinio esperado y propio del ser humano no son considerados tales, y son, por lo tanto, y en el mejor de los casos, seres merecedores de atención y cuidados, pero desde la pers- 
pectiva de un ser menor e incompleto en su ascenso a lo esencialmente humano. (Tamarit, 2005, p. S182)

En este marco, se contempla a la escuela como una institución encargada de desarrollar en los hijos de los humanos, fundamentalmente, las capacidades racionales. La calidad del servicio educativo tiene como referente primordial el puntaje en pruebas nacionales e internacionales que miden la competencia matemática, la competencia científica, la competencia en el manejo del lenguaje escrito, pero que nada dicen del desarrollo de la sensibilidad artística, de la empatía, del respeto por el medio ambiente, por ejemplo; pruebas en las que los estudiantes con discapacidad, por más que estén matriculados en instituciones educativas de básica regular, son invisibles.

Mientras la escuela siga siendo competitiva, mientras siga priorizando lo racional sobre la trascendencia comunicativa (más allá del lenguaje escrito), seguirá siendo una escuela segregacionista con fachada de inclusión.

El contemplar a la educación de la persona con discapacidad intelectual desde el enfoque de la calidad de vida se presenta como una oportunidad de renovación profunda de la escuela; ya es momento de que se provoque esa crítica enriquecedora al modelo dominante, que reclamaba Fortes en 1994.

\section{A modo de conclusión}

El compromiso de los educadores como compañeros de camino de las personas con discapacidad intelectual exige, en primer lugar, reconocer que ellas, y sólo ellas, son las protagonistas de su biografía. Es tarea de los profesionales de la educación propiciar las estrategias pedagógicas que favorezcan la calidad de vida a la vez de redefinir la escuela, de tal forma que deje de ser competitiva, que deje de contemplar en el intelecto la esencia del ser humano y que respete el derecho de toda persona a ser el artífice de su propia existencia. 


\section{Referencias}

Asensio, J. M., Bárcena, F. y Mélich, J.C. (200 I ). Educación, vida humana y biopoder. En G. Vásquez (Ed.), Educación y calidad de vida (pp. 8I-II5). Madrid: Complutense.

Bandura, A. (1999). Ejercicio de la eficacia personal y colectiva en sociedades cambiantes. En A. Bandura (Ed.), Auto-eficacia: cómo afrontamos los cambios de la sociedad actual (pp. 19-54). Bilbao: Desclée de Brouwer.

Fortes, A. (1994). Teoría y práctica de la integración escolar: los límites de un éxito. Málaga: Aljibe.

Frankl, V. ( 1984). Ante el vacío existencial. Barcelona: Herder.

Fritht, U. (|99|): Autismo, hacia una explicación del enigma. Madrid: Alianza.

Fullat, O. (2000). Filosofía de la educación. Madrid: Síntesis.

Gómez-Vela, M., Verdugo, M.A. y Canal, R. (2002): Evaluación de la calidad de vida de adultos con discapacidad intelectual en servicios residenciales comunitarios. Revista de Psicología General y Aplicada, 55 (4), 59I -602. Recuperado de: http:// www.infoautismo.es/wp-content/uploads/20 I5/I0/18._Art\%C3\%ADculo. pdf

Ministerio de Educación. (20|2). Educación básica especial y educación inclusiva: Balance y perspectiva. Recuperado de: http://www.minedu.gob.pe/minedu/ archivos/a/002/05-bibliografia-para-ebe/9-educacion-basica-especial-yeducacion-inclusiva-balance-y-perspectivas.pdf

Peralta, F. y Arellano, A. (20|4). La autodeterminación de las personas con discapacidad intelectual: situación actual en España. CES Psicología, 7 (2), 59 77. Recuperado de: http://www.redalyc.org/pdf/4235/423539424006.pdf

Reading, R. y Reynolds, S. (200 I). Debt, social disadvantage and maternal depression. Social Science \& Medicine, 53, 44I-453

Schalock, R. L. y Verdugo, M. A. (2007). El concepto de calidad de vida en los servicios y apoyos para personas con discapacidad intelectual. Siglo Cero, 38 (4), $21-36$. 
Seligman, M. (1989). Indefensión: En la depresión, el desarrollo y la muerte. Madrid: Debate.

Tamarit, J. (2005). Autismo: modelos educativos para una vida de calidad. Revista de Neurología, 40 (Supl. I), SI8I-SI86. Recuperado de: http://eds.a.ebscohost. com/eds/pdfviewer/pdfviewer?sid=f4e6a33d-cc3a-4c93-8784-fac7 I ba93fe0 \%40sessionmgr4009\&vid = 10\&hid $=4202$

Vehmas, S. (2004). Análisis ético del concepto de discapacidad. Siglo Cero, 35 (4), $50-68$.

Verdugo, M.A. (2009). El cambio educativo desde una perspectiva de la calidad de vida. Revista de Educación, 349, 23-42. Recuperado de: www.revistaeducacion. mec.es/re349/re349_02.pdf

Wehmeyer, M. (2005). Self-Determination and individuals with severe disabilities: Re-examining meanings and misinterpretations. Research \& Practice for Persons with Severe Disabilities, 30 (3), I I3- 120. Recuperado de: http://www. beachcenter.org/Research/FullArticles/PDFMehmeyer_2005.pdf

Wehmeyer, M. (2009). Autodeterminación y la Tercera Generación de prácticas de inclusión. Revista de Educación, 349, 45-67. Recuperado de: www. revistaeducacion.mec.es/re349/re349_03.pdf 